Article

\title{
Chemical Modification of Poly(Vinyl Alcohol) in Water
}

\section{Houssein Awada * and Claude Daneault}

Centre de Recherche sur les Matériaux Lignocellulosiques (CRML), Université du Québec à Trois-Rivières, 3351, Boulevard des Forges, Trois-Rivières, QC G9A 5H7, Canada;

E-Mail: claude.daneault@uqtr.ca

* Author to whom correspondence should be addressed; E-Mail: houssein.awada@uqtr.ca or houssein_awada@hotmail.com; Tel.: +1-819-376-5011 (ext. 4516); Fax: +1-819-376-5148.

Academic Editor: Samuel B. Adeloju

Received: 14 September 2015 / Accepted: 9 October 2015 / Published: 20 October 2015

\begin{abstract}
Partial chemical modification of poly(vinyl alcohol) (PVA) was performed through tosylation followed by azidation. Amine functional PVA was also prepared by grafting propargylamine using click chemistry reaction. Through this approach, a tosyl group (a good leaving group), azide group (a group used in click chemistry) and amine group (a group used for amidation) were attached to PVA polymer chains. The three chemical modifications were performed in water. FTIR and XPS analysis confirmed the chemical modification after each step. Thermogravimetric analysis (TGA) was used to study the thermal stability of the modified PVA.
\end{abstract}

Keywords: poly(vinyl alcohol); chemical modification; click chemistry; green chemistry

\section{Introduction}

Polyvinyl alcohol (PVA) is the largest volume synthetic water-soluble polymer produced in the world [1]. PVA has excellent chemical resistance, a good mechanical property, a good film forming capability and an excellent biocompatibility [2]. In addition, PVA is biodegradable in the presence of suitable microorganisms. The several useful properties of PVA result in broad industrial use and make it particularly interesting to elaborate environmentally friendly materials [3-5]. However, PVA can be considered as an inert material. The introduction of chemical functionalities is necessary to improve its reactivity. Chemical modifications of PVA, which can be made through its hydroxyl groups, are 
reviewed in the literature. The most common PVA modification reactions are esterification, etherification or acetalization of the hydroxyl groups [6].

Particular attention has been recently devoted to the chemical modification of natural and synthetic polymers using a green solvent due to environmental factors. It is evident that water is the most available environmentally friendly and inexpensive solvent [7]. The present paper describes the incorporation of chemical group in PVA polymer chain using water as solvent. We mainly focused on the incorporation of tosyl, azide and amine groups leading to the enhancing of the reactivity of PVA.

The tosyl and azide groups were introduced in the PVA polymer chain using pyridine and DMF as solvent $[8,9]$. Tosyl moiety is an excellent leaving group in nucleophilic substitution reactions and can, for instance, be substituted by halogens, azide, or amines. Tosylation of cellulose and of lignin in water or in eco-friendly medium was reported in the literature [10-12]. To the best of our knowledge, the tosylation of PVA in aqueous media has not yet been reported.

Moreover, the presence of azide moiety is of considerable utility in the generation of other functionalities, e.g., amines via reduction, imines via rearrangement, triazoles and other heterocycles via cycloaddition [13-15]. Herein, we investigate the use of water as solvent during the azidation reaction. Finally, we made a reaction between the azido PVA and the porpargylamine by click reaction in order to introduce the amine function on the PVA polymer chain. The possibility to perform the click reaction in water has been reported [16]. The presence of amine moiety allows the reaction of PVA with polymer or molecules containing acid carboxylic function by amidation. For example, the formation of an amide function between modified PVA and cellulose fibers containing a high amount of carboxylic acid can be used to elaborate a homogenous biocomposite. The amidation can also be performed in water using a carbodiimide mediated pathway [17].

\section{Experimental Section}

\subsection{Materials}

Triethylamine $\left(\mathrm{Et}_{3} \mathrm{~N}\right)$, p-toluenesulfonyl chloride $(98 \%$, Tosyl or TsCl), were purchased from Sigma-Aldrich, (Oakville, ON, Canada) (purity = 99\%). Sodium azide (99\%), propargylamine (98\%), sodium ascorbate (99\%) were supplied by Alfa Aesar, (Ward Hill, MA, USA). Copper sulfate pentahydrate $\left(\mathrm{CuSO}_{4} \cdot 5 \mathrm{H}_{2} \mathrm{O}\right)$ was obtained from Caledon. Poly(vinyl alcohol) (degree hydrolysis $99 \%$, molecular weight $\mathrm{Mw}=77,000 \mathrm{~g} / \mathrm{mol}$ ) was acquired from Avantor, (Center Valley, PA, USA). Dialysis tubings (MWCO 6000-8000 dalton) were purchased from Biodesign, (New York, NY, USA) All of these products were used as received.

\subsection{Methods}

\subsubsection{Preparation of PVA Solution}

Ten percent $(w / v)$ of PVA solution was prepared by adding the PVA to deionized water at $80{ }^{\circ} \mathrm{C}$ and stirring for $2 \mathrm{~h}$. 


\subsubsection{Synthesis of Tosyl Functionalized PVA (PVA-Ts)}

A solution $(100 \mathrm{~mL})$ containing PVA ( $2 \mathrm{~g})$ was mixed with $4.33 \mathrm{~g}$ of $\mathrm{TsCl}$ ( 1 equiv) in the presence of $10.4 \mathrm{~mL}$ of $\mathrm{Et}_{3} \mathrm{~N}$ (3.45 equiv). After $24 \mathrm{~h}$ of stirring at room temperature, the mixture was composed of unreacted TsCl, PVA-Ts and $\mathrm{Et}_{3} \mathrm{~N}$. Two ways were investigated for the next chemical modifications:

a. Filtration to remove excess of unreacted $\mathrm{TsCl}$. The filtrated solution (PVA-Ts $+\mathrm{Et}_{3} \mathrm{~N}$ ) will be used for the azidation.

b. Concentration of the mixture in a rotary evaporator and precipitation of PVA-Ts with ethanol followed by filtration and washing with hot ethanol. A part of the product was dried at room temperature for further analysis. The modified PVA was dissolved in hot water directly after precipitation.

\subsubsection{Synthesis of Azide Functionalized PVA (PVA-N 3 )}

Sodium azide ( $3.08 \mathrm{~g}, 1$ equiv) was added to a water solution $(100 \mathrm{~mL})$ containing $2 \mathrm{~g}$ of PVA-Ts (solution obtained by the way a or b). The solution was stirred at $80^{\circ} \mathrm{C}$ for $48 \mathrm{~h}$. After $48 \mathrm{~h}$ a solution was dialyzed in deionized water to remove excess $\mathrm{NaN}_{3}$ and by-product for $72 \mathrm{~h}$. The surrounding water used for the dialysis was changed every $2 \mathrm{~h}$. A film of modified PVA was formed for characterization. Another solution was directly used for the next modification without dialysis.

\subsubsection{Synthesis of Amine Functionalized PVA (PVA-NH2)}

Propargylamine (3.6 mL, 1 equiv) was mixed with PVA-N 3 (2 g) in water $(100 \mathrm{~mL})$. Sodium ascorbate (105 mg, $0.53 \mathrm{mmol}$ ) was dissolved in $5 \mathrm{~mL}$ of water and added to reaction medium. Copper sulfate pentahydrate $(65 \mathrm{mg}, 0.26 \mathrm{mmol}$ ), dissolved in $5 \mathrm{~mL}$ of water was also added to the solution. The mixture was then left to react under mechanical stirring for $48 \mathrm{~h}$ at room temperature. After that, the reaction product was dialyzed to remove excess chemical products as described above. A film of the modified PVA was formed for characterization.

Figure 1 summarizes the synthetic strategy chosen for the chemical modification of PVA.

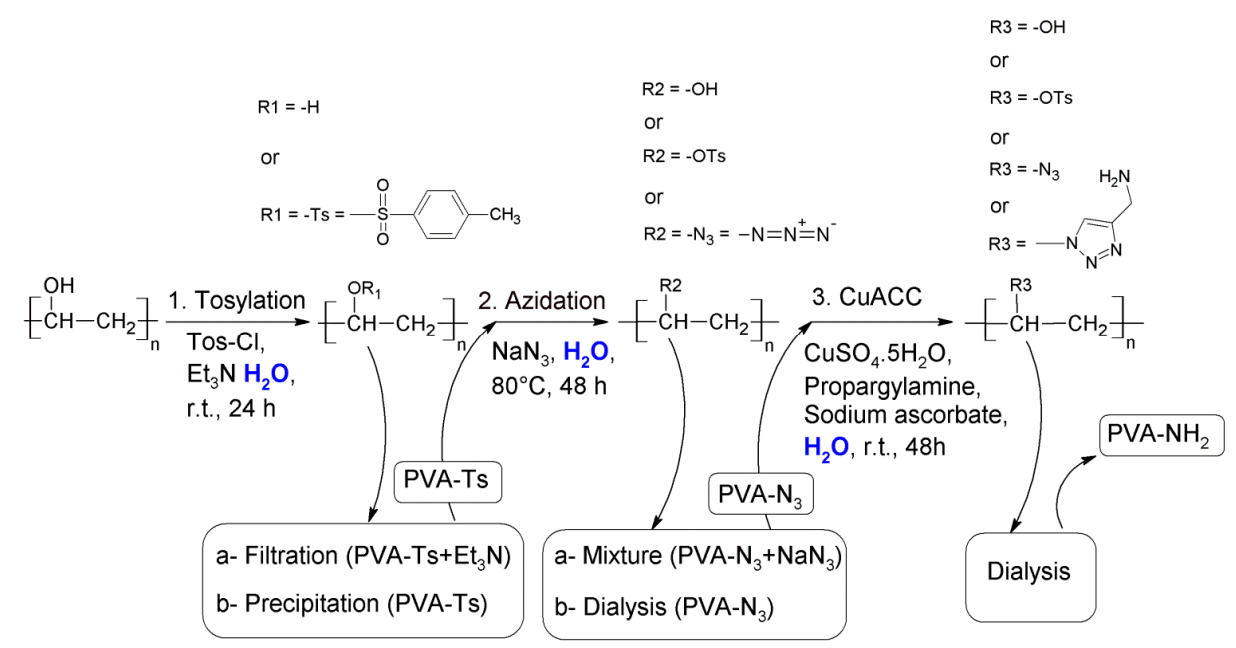

Figure 1. Synthetic strategy using for polyvinyl alcohol (PVA) modification in water. 


\subsection{Characterization}

A Perkin Elmer 1000 FTIR spectrometer (Perkin-Elmer, Ltd., Buckinghamshire, UK) equipped with Spectrum software was used to perform FTIR analysis. The spectra were obtained by preparing dried $\mathrm{KBr}$ powder pellets containing $2 \% \mathrm{w} / \mathrm{w}$ of the investigated sample. The discs were scanned over the range 4000 to $400 \mathrm{~cm}^{-1}$ with a total of 16 scans at a resolution of $\pm 4 \mathrm{~cm}^{-1}$.

XPS experiments were carried out using a Kratos Axis Ultra spectrometer (Kratos, Manchester, UK). A $225 \mathrm{~W}$ monochromatic aluminum source (Alk $\alpha$ ) was used. Survey scans were taken with $1.0 \mathrm{eV}$ step and $160 \mathrm{eV}$ analyzer pass energy, while the high resolution regional spectra were recorded with $0.1 \mathrm{eV}$ step and $40 \mathrm{eV}$ pass energy. The pressure was typically $10^{-9}$ Torr. An area of $2 \mathrm{~mm}^{2}$ at three different spots was analyzed in order to average over the sample, to avoid any bias due to an eventual heterogeneity. The position of the detector was at an angle of $90^{\circ}$ to the sample surface. Deconvolution analysis was performed with casa XPS 2.3.15 (Kratos, Manchester, UK).

Thermal stability analysis (TGA) data of the samples was taken on Perkin-Elmer (Pyris Diamond) Thermoanalyzer (Perkin-Elmer, Yokohama, Japan) in nitrogen atmosphere. Samples were heated in open alumina pans. First the sample was heated from room temperature to $105{ }^{\circ} \mathrm{C}$ at heating rate of $20{ }^{\circ} \mathrm{C} / \mathrm{min}$. Then samples were maintained at $105{ }^{\circ} \mathrm{C}$ during $15 \mathrm{~min}$ to remove water. After that, samples were heated from $105^{\circ} \mathrm{C}$ to $575^{\circ} \mathrm{C}$ at a heating rate of $5{ }^{\circ} \mathrm{C} / \mathrm{min}$. Finally, samples were heated from $575{ }^{\circ} \mathrm{C}$ to $950{ }^{\circ} \mathrm{C}$ under air at a heating rate of $10^{\circ} \mathrm{C} / \mathrm{min}$.

\section{Results and Discussion}

\subsection{FTIR Analysis}

Chemical modifications of PVA was monitored by FTIR. Figure 2 represents FTIR spectrum of: (a) unmodified PVA; (b) tosylated PVA (PVA-Ts); (c) azidated PVA (PVA-N $)$ and (d) PVA after the click reaction with propargylamine $\left(\mathrm{PVA}^{-\mathrm{NH}_{2}}\right)$.

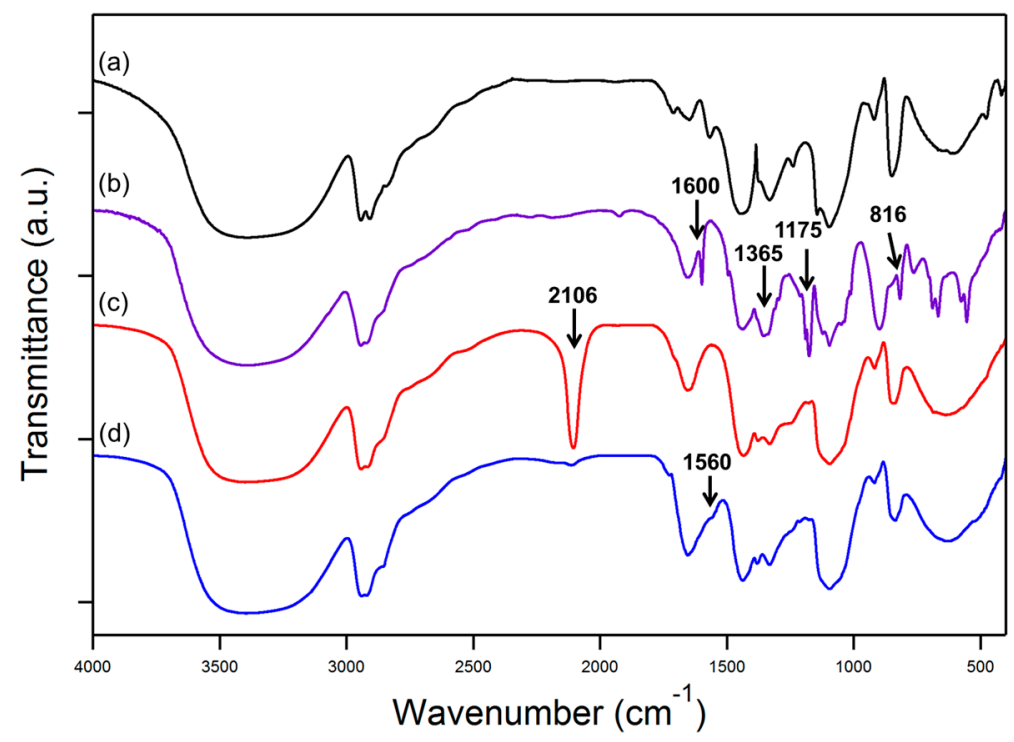

Figure 2. FTIR spectra of (a) unmodified PVA; (b) tosylated PVA (PVA-Ts); (c) azidated PVA (PVA-N 3 ) and (d) PVA after click reaction with propargylamine ( $\left.\mathrm{PVA}-\mathrm{NH}_{2}\right)$. 
The FTIR analysis of unmodified PVA (Figure 2a) revealed characteristic PVA spectra that are in agreement with the literature [18]. We can clearly see the presence of a large peak at $3400 \mathrm{~cm}^{-1}$. This peak is linked to the stretching of $\mathrm{O}-\mathrm{H}$ from the intramolecular and intermolecular hydrogen bonds. The peaks observed at $2840 \mathrm{~cm}^{-1}$ and $2920 \mathrm{~cm}^{-1}$ are respectively related to the symmetric and antisymmetric stretching vibrational of $\mathrm{C}-\mathrm{H}$ from alkyl groups. Comparing with the unmodified PVA, after reaction with the tosyl group (Figure $2 \mathrm{~b}$ ), one can observe the appearance of new peaks. The new peaks appeared mainly at $1600 \mathrm{~cm}^{-1}, 1365 \mathrm{~cm}^{-1}, 1175 \mathrm{~cm}^{-1}$ and $816 \mathrm{~cm}^{-1}$. The peak at $1600 \mathrm{~cm}^{-1}$ may be assigned to the aromatic $\mathrm{C}=\mathrm{C}$ stretching group. The two new peaks at $1365 \mathrm{~cm}^{-1}$ and $1175 \mathrm{~cm}^{-1} \mathrm{can}$ be related to the $\mathrm{S}=\mathrm{O}$ group, and the peak at $816 \mathrm{~cm}^{-1}$ can be related to the $\mathrm{C}-\mathrm{O}-\mathrm{S}$ bonds [19].

Two ways were investigated for the azidation reaction after the tosylation. The FTIR spectra of the PVA-N 3 are similar and compared to the Figure $2 \mathrm{c}$. Indeed, Figure $2 \mathrm{c}$ showed the disappearance of the entire peaks related to the presence of tosyl and the appearance of a new peak at $2106 \mathrm{~cm}^{-1}$. The peak at $2106 \mathrm{~cm}^{-1}$ is assigned to the azide antisymmetric stretch. These results suggested the consumption of the tosyl group and confirmed the introducing of the azide function on the PVA backbone. This result indicated that, for azidation reaction, the precipitation of PVA-Ts is not necessary. Moreover, the presence of $\mathrm{Et}_{3} \mathrm{~N}$ does not influence the azidation reaction. In addition, avoiding the precipitation allowed gain time and used less energy. Also, in the case of using a click reaction to introduce amine function on the PVA backbone, two ways were investigated after azidation. The first one consisted of undertaking the reaction in the presence of the excess of $\mathrm{NaN}_{3}$. The second way consisted of removing $\mathrm{NaN}_{3}$ excess by dialysis. FTIR analysis (Figure 2d) showed identical results. We mainly notice the decreased intensity of the peak at $2106 \mathrm{~cm}^{-1}$ and the appearance of a new peak at $1560 \mathrm{~cm}^{-1}$. This new peak should be related to the primary amine function. This result confirms the introducing of the amine function on the backbone of PVA. The first way enables us to gain the time wasted during the dialysis step. A comparison between the mass yield for way a (75\%) and the way b (40\%) showed that the filtration offered another advantage compared to the precipitation.

The FTIR analysis proved that the chemical modification of PVA was confirmed. The different step of the chemical modification was also supported by XPS analysis.

\subsection{XPS Analysis}

After modification, PVA was characterized by XPS. Figure 3 shows the survey spectra of unmodified PVA and of PVA after each chemical modification. The elements compositions from each spectrum were calculated and listed in Table 1.

For unmodified PVA, only characteristic peaks of $\mathrm{C}$ and $\mathrm{O}$ can be found. After tosylation (Figure 3b), the XPS spectrum showed two additional peaks at $169 \mathrm{eV}$ and $233 \mathrm{eV}$ which are assigned to the binding energy of $S_{2 p}$ and $S_{2 s}$ respectively. These peaks are related to the presence of the tosyl group.

For the tosylation we measured the degree of substitution (DS) from the XPS data using the following method:

$\%[\mathrm{Ts}]=\%[\mathrm{~S}]=3.27$

$\%\left[\mathrm{O}_{\mathrm{Ts}}\right]=2 \times 3.27=6.54$ (each molecule of Ts contains 2 Oxygen atoms) 
$\%[\mathrm{OvA}]=\%[1 \mathrm{VA}]=24.81-6.54=18.27(\mathrm{VA}=$ unit of polyvinyl alcohol; each molecule of VA contains 1 Oxygen atom)

Finally the DS of tosylation is obtained by dividing \% [tos] per \% [One VA]

$\mathrm{DS}=[\mathrm{Ts}] /[1 \mathrm{VA}]=0.1789$

This value is in good agreement with the literature [10].

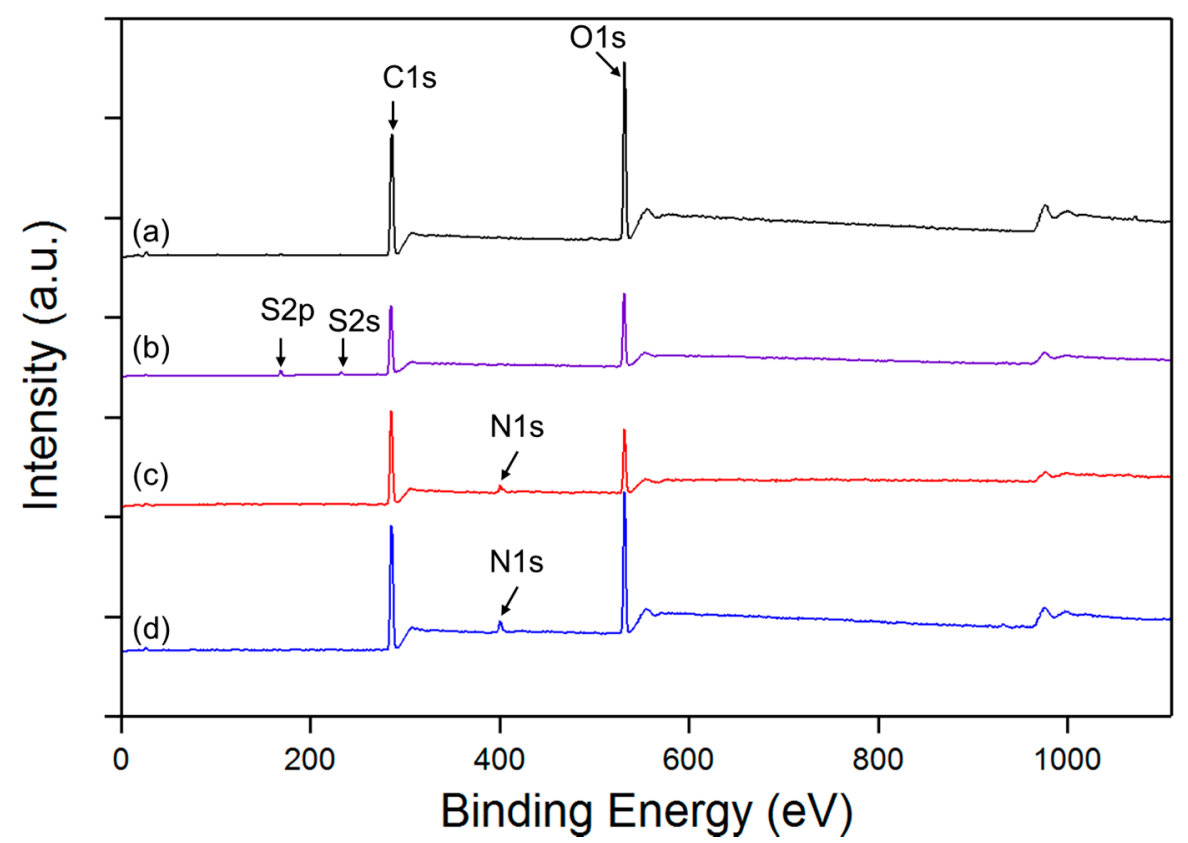

Figure 3. XPS spectra of (a) unmodified PVA; (b) tosylated PVA (PVA-Ts); (c) azidated PVA (PVA-N 3 ) and (d) PVA after click reaction with propargylamine (PVA-NH2).

Table 1. Elements compositions of unmodified PVA and PVA after each chemical functionalization.

\begin{tabular}{ccccc}
\hline Sample & $\mathbf{C \%}$ & $\mathbf{O \%}$ & $\mathbf{S \%}$ & $\mathbf{N \%}$ \\
\hline PVA & 69.95 & 30.05 & - & - \\
PVA-Ts & 71.92 & 24.81 & 3.27 & - \\
PVA-N & 77.42 & 17.74 & - & 4.84 \\
PVA-NH $_{2}$ & 72.15 & 23.82 & - & 4.03 \\
\hline
\end{tabular}

After azidation, the characteristic peaks of $\mathrm{S}$ disappeared in the XPS spectrum (Figure 3c) suggesting the consumption of the tosyl group. In addition, the XPS spectrum showed an additional peak at $401 \mathrm{eV}$ which is assigned to the binding energy of $\mathrm{N}_{1 \mathrm{~s}}$. This peak suggested the introducing of the azide group on PVA polymer chains. After click reaction, (Figure 3d) XPS spectra showed the same chemical composition (presence of $\mathrm{C}, \mathrm{O}$ and $\mathrm{N}$ ) with different atomic percentage. In order to confirm the click reaction, a comparison between the high resolution spectrum of the $\mathrm{N}_{1 \mathrm{~s}}$ before and after click reaction was shown in Figure 4.

In Figure $4 \mathrm{a}$ we observed the characteristic $\mathrm{N}_{3}$ peak doublet at $404.48 \mathrm{eV}$ and $400.76 \mathrm{eV}$ with a peak area of 2:1. The larger intensity peak at $400.76 \mathrm{eV}$ results from the two outer nitrogen atoms of the azide functional group, and the smaller peak at $404.8 \mathrm{eV}$ (assigned to azides) is characteristic of the electron poor middle nitrogen [20,21]. After click reaction (Figure 4b), the peak at $404.48 \mathrm{eV}$ is 
reduced and the peak at $400.76 \mathrm{eV}$ is shifted to $400.49 \mathrm{eV}$, which corresponds to the appearance of the triazole. This modification of the $\mathrm{N}_{1 \mathrm{~s}}$, in good agreement with the literature, indicated the formation of the triazole [22-24].

The XPS results complement the FTIR analysis, providing strong evidence in support of each step of PVA chemical modification.
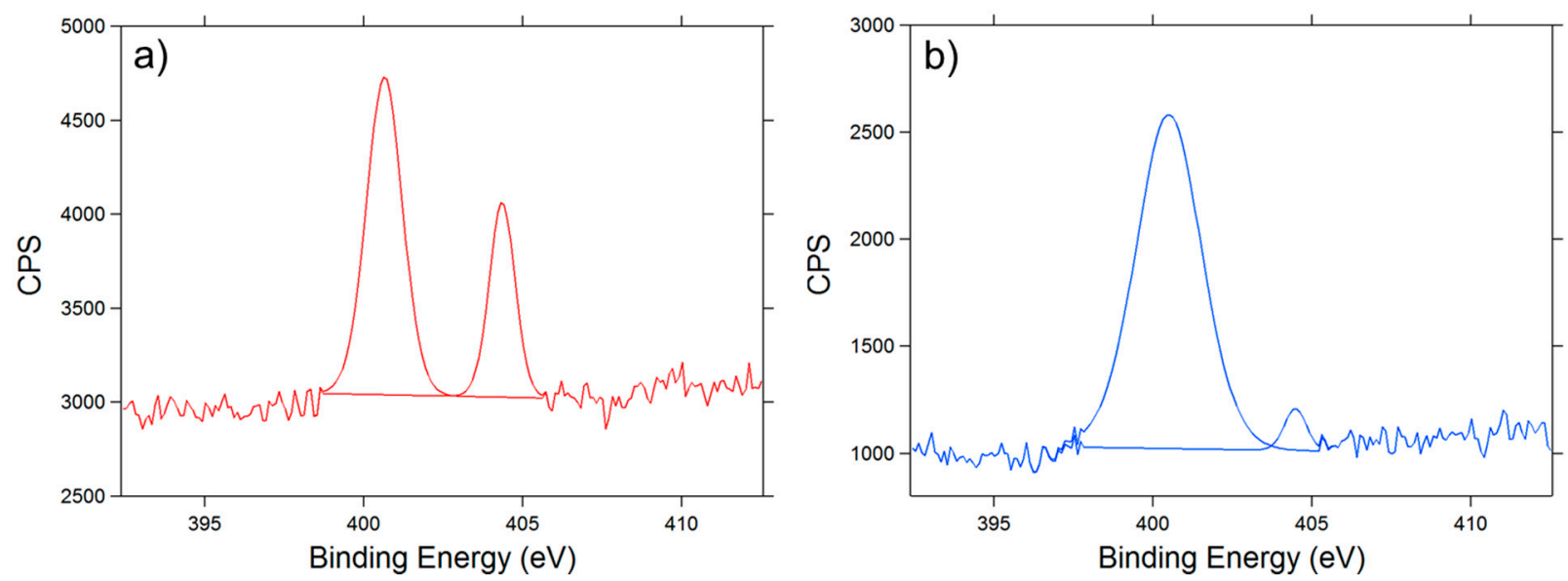

Figure 4. High-resolution XPS $\mathrm{N}_{1 \text { s }}$ core level spectra of (a) PVA-N 3 and (b) PVA-NH2.

\subsection{TGA Analysis}

TGA analysis was also used to investigate the influence of the chemical modification on thermal stability of PVA. The results from TGA are presented in Figure 5. The deflection temperatures are shown in Table 2.

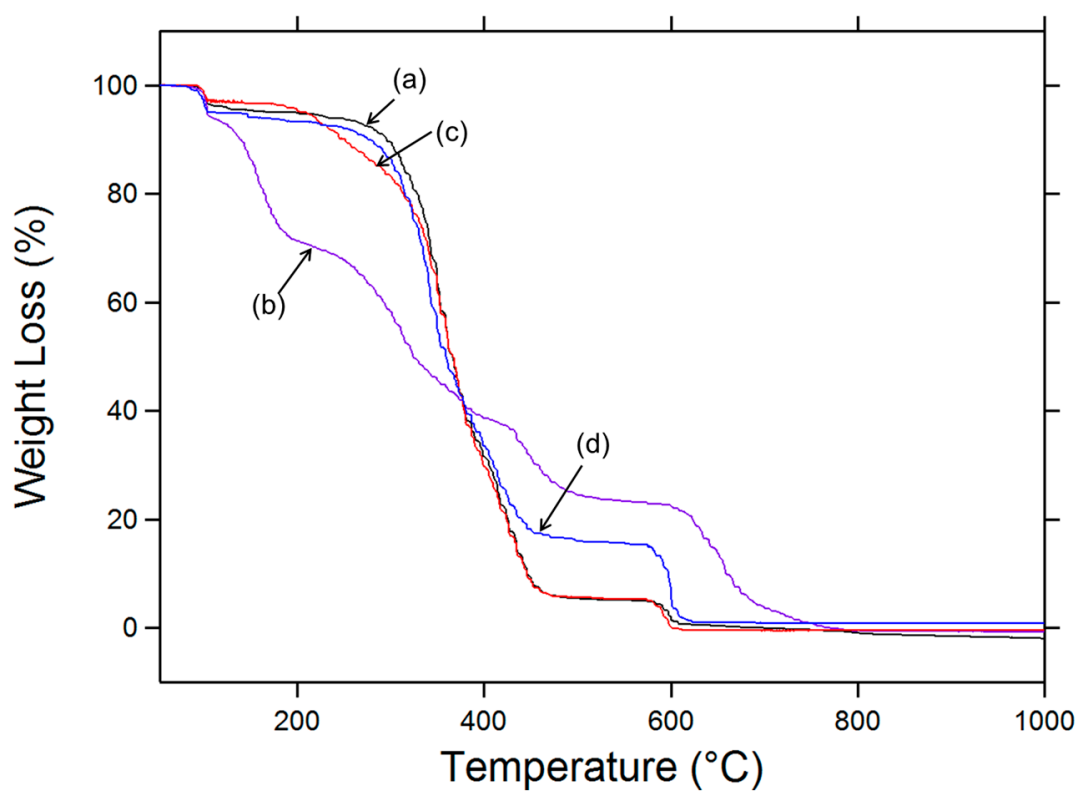

Figure 5. Thermal stability analysis (TGA) curves of (a) unmodified PVA; (b) PVA-Ts; (c) PVA-N 3 and (d) PVA-NH2. 
Table 2. The data obtained from TGA and DTG curves of unmodified PVA, PVA-Ts, PVA-N3 and PVA-NH2.

\begin{tabular}{ccccc}
\hline Sample & $\begin{array}{c}\boldsymbol{T}_{\text {Weight loss (10\%) }} \\
\left({ }^{\circ} \mathbf{C}\right)\end{array}$ & $\boldsymbol{T}_{\text {peak I }}\left({ }^{\circ} \mathbf{C}\right)$ & $\boldsymbol{T}_{\text {peak II }}\left({ }^{\circ} \mathbf{C}\right)$ & $\boldsymbol{T}_{\text {peak III }}\left({ }^{\circ} \mathbf{C}\right)$ \\
\hline PVA & 295 & - & 351 & 423 \\
PVA-Ts & 139 & 161 & 320 & 434 \\
PVA-N & 244 & - & 352 & 422 \\
PVA-NH & 275 & - & 337 & 405 \\
\hline
\end{tabular}

* $T_{\text {Weight loss (10\%): }}$ Temperature of $10 \%$ of weight loss for all the samples.

From TGA results, we noticed initial weight loss until 5\% for all of PVA samples when the temperature achieved $105{ }^{\circ} \mathrm{C}$. This loss is due to the evaporation of the adsorbed water. After $105{ }^{\circ} \mathrm{C}$, we clearly observed a difference between the PVA-Ts and the other samples. For the unmodified PVA, two inflexions were observed with a maximum at $351{ }^{\circ} \mathrm{C}$ and $423{ }^{\circ} \mathrm{C}$ corresponding to two distinct decomposition steps. The first temperature can be assigned to the side chain of the PVA while the second temperature can be related to a decomposition of the main chain of PVA [25]. The loss of $10 \%$ of PVA was recorded at $295{ }^{\circ} \mathrm{C}$. PVA-Ts showed the presence of three inflexions at $161{ }^{\circ} \mathrm{C}, 320{ }^{\circ} \mathrm{C}$ and $434{ }^{\circ} \mathrm{C}$ correspond to three distinct decomposition steps. The appearance of the first temperature of degradation and the shift of the other deflections temperature should be related to the presence of the tosyl groups. The loss of $10 \%$ of PVA-Ts was recorded early at $139{ }^{\circ} \mathrm{C}$. The tosyl can modify the intermolecular force between PVA chains. After azidation (Figure 5c), the inflexion at $161{ }^{\circ} \mathrm{C}$ was disappeared due to the consumption of the tosyl group. Comparing to unmodified PVA, the thermal decomposition of PVA-N 3 started at a lower temperature $\left(T_{\text {Weight }}\right.$ loss $(10 \%)=244{ }^{\circ} \mathrm{C}$ comparing to $T_{\text {Weight loss (10\%) }}=295{ }^{\circ} \mathrm{C}$ for PVA). Finally for PVA-NH , TGA analysis (Figure $5 \mathrm{~d}$ ) showed an increase of the thermal stability compared to PVA-N $\mathrm{N}_{3}$. The shape of the curve became very close to unmodified PVA. The $T_{\text {Weight loss (10\%) }}$ increased to $275^{\circ} \mathrm{C}$. This increase can be related to intermolecular interactions due to the incorporation of the amine group.

These results showed that the incorporation of azide and amine groups slightly modified the thermal stability of PVA. The thermal stability was more influenced in the case of tosylated PVA which was less thermally stable when compared to the other modified PVA.

\section{Conclusions}

The chemical modification of PVA in water was performed. We showed the possibility to incorporate tosyl group on PVA polymer chain. After tosylation, we showed the possibility to substitute the tosyl by the azide group. We demonstrated that the presence of $\mathrm{Et}_{3} \mathrm{~N}$ in the media during the azidation did not cause problems for the reaction. Consequently, we proposed an easy and ecological way for the azidation reaction to take place. We also transformed the PVA into PVA containing amine function groups. The modified PVA can be prepared and obtained in water. The precipitation step is not necessary in all of our methods. FTIR and XPS tools proved the chemical modification of PVA. TGA analysis showed that the presence of $\mathrm{N}_{3}$ and $\mathrm{NH}_{2}$ slightly modified the thermal stability of PVA. In comparison, tosylated PVA had a lower thermal stability. While the use of water as solvent was demonstrated in the literature during tosylation and click chemistry on other 
polymers (i.e., celluloses), azidation in water was used for the first time. The intermediates (PVA-Tos and PVA-N 3 ) and the final product (PVA-NH$)$ can be used to incorporate new functionalities to PVA (i.e., add value) or to make a composite with another polymer (new application of PVA). Further studies using amino-group-containing PVA to prepare nanocomposite based on cellulose nanofibrils and PVA are now in progress. In the future, we will focus on the reaction between oxidized cellulose containing high amounts of carboxylic acid (micro and nano-fibrillar cellulose obtained by TEMPO oxidation) and PVA containing the amine group in water. The formation of the amide group should increase the homogeneity of such a product.

\section{Acknowledgments}

The authors gratefully acknowledge the support of the Green Fibre Network and the Natural Science and Engineering Research Council of Canada (NSERC).

\section{Author Contributions}

Planning and performing the experiments: Houssein Awada; Data analysis, data interpretation and writing the manuscript: Houssein Awada; Supervising the project and revision of the manuscript: Claude Daneault.

\section{Conflicts of Interest}

The authors declare no conflict of interest.

\section{References}

1. Ding, B.; Kim, H.Y.; Lee, S.C.; Shao, C.L.; Lee, D.R.; Park, S.J.; Kwag, G.B.; Choi, K.J. Preparation and characterization of a nanoscale poly(vinyl alcohol) fiber aggregate produced by an electrospinning method. J. Polym. Sci. Part B 2002, 40, 1261-1268.

2. Shi, R.; Bi, J.; Zhang, Z.; Zhu, A.; Chen, D.; Zhou, X.; Zhang, L.; Tian, W. The effect of citric acid on the structural properties and cytotoxicity of the polyvinyl alcohol/starch films when molding at high temperature. Carbohydr. Polym. 2008, 74, 763-770.

3. Chiellini, E.; Corti, A.; D’Antone, S.; Solaro, R. Biodegradation of poly(vinyl alcohol) based materials. Prog. Polym. Sci. 2008, 28, 963-1014.

4. Thomas, L.V.; Arun, U.; Remya, S.; Nair, P.D. A biodegradable and biocompatible PVA-Citric acid polyester with potential applications as matrix for vascular tissue engineering. J. Mater. Sci. Mater. Med. 2009, 20, S259-S269.

5. Rescignanoa, N.; Fortunati, E.; Montesano, S.; Emiliani, C.; Kenny, J.M.; Martino, S.; Armentano, I. PVA bio-nanocomposites: A new take-off using cellulose nanocrystals and PLGA nanoparticles. Carbohydr. Polym. 2014, 99, 47-58.

6. Gaina, C.; Ursache, O.; Gaina, V.; Ionita, D. Study on the Chemical Modification of Poly(Vinyl Alcohol) with 4-Maleimidophenyl Isocyanate. Polym. Plast. Technol. Eng. 2012, 51, 65-70.

7. Erdmenger, T.; Sanchez, C.G.; Vitz, J.; Hoogenboom, R.; Schubert, U.S. Recent developments in the utilization of green solvents in polymer chemistry. Chem. Soc. Rev. 2010, 39, 3317-3333. 
8. Gacal, B.N.; Koz, B.; Gacal, B.; Kiskan, B.; Erdogan, M.; Yaggi, Y. Pyrene Functional Poly(vinyl alcohol) by "Click" Chemistry. J. Polym. Sci. Part A 2009, 47, 1317-1326.

9. Kara, S.; Gacal, B.; Tunc, D.; Yagci, Y.; Pekcan, O. Sorption and desorption of PVA-pyrene chains in and out of agarose Gel. J. Fluoresc. 2012, 22, 1073-1080.

10. Elchinger, P.-H.; Faugeras, P.-A.; Zerrouki, C.; Montplaisir, D.; Brouillette, F.; Zerrouki, R. Tosylcellulose synthesis in aqueous medium. Green Chem. 2012, 14, 3126-3131.

11. Diop, A.; Awada, H.; Zerrouki, R.; Daneault, C.; Montplaisir, D. Tosylation and Characterization of Lignin in Water. Ind. Eng. Chem. Res. 2014, 53, 16771-16776.

12. Schmidt, S.; Liebert, T.; Heinze, T. Synthesis of soluble cellulose tosylates in an eco-friendly medium. Green Chem. 2014, 16, 1941-1946.

13. Kolb, H.C.; Finn, M.G.; Sharpless, K.B. Click Chemistry: Diverse Chemical Function from a Few Good Reactions. Angew. Chem. 2001, 40, 2004-2021.

14. Kaneko, Y.; Matsuda, S.; Kadokawa, J. Chemoenzymatic synthesis of amylose-grafted poly(vinyl alcohol). Polym. Chem. 2010, 1, 193-197.

15. Pramanik, S.; Reddy, R.R.; Ghorai, P.; Transition Metal-Free Generation of N-Unsubstituted Imines from Benzyl Azides: Synthesis of $N$-Unsubstituted Homoallylic Amines. J. Org. Chem. 2014, 80, 3656-3663.

16. Elchinger, P.-H.; Awada, H.; Zerrouki, C.; Montplaisir, D.; Zerrouki, R. Kraft Pulp-Starch Covalent Linking: A Promising Route to a New Material. Ind. Eng. Chem. Res. 2014, 53, 7604-7610.

17. Nakajima, N.; Ikada, Y. Mechanism of Amide Formation by Carbodiimide for Bioconjugation in Aqueous Media. Bioconjugate Chem. 1995, 6, 123-130.

18. Chen, J.; Li, Y.; Zhang, Y.; Zhu, Y. Preparation and characterization of graphene oxide reinforced PVA film with boric acid as crosslinker. J. Appl. Polym. Sci. 2015, 132, 42000-42008.

19. Kavitha, A.S.; Kiruthika, R.; Kalaivani, A.; Synthesis, S. Characterization and Antimicrobial Studies of Tosyl Esters of Carboxylic Acid. Int. J. Sci. Res. Publ. 2014, 4, 1-4.

20. Gallardo, I.F.; Webb, L.J. Tethering Hydrophobic Peptides to Functionalized Self-Assembled Monolayers on Gold through Two Chemical Linkers Using the Huisgen Cycloaddition. Langmuir 2010, 26, 18959-18966.

21. Daugaard, A.E.; Hvilsted, S.; Hansen, T.S.; Larsen, N.B. Conductive Polymer Functionalization by Click Chemistry. Macromolecules 2008, 41, 4321-4327.

22. Darlatta, E.; Traulsen, C.H.-H.; Poppenberg, J.; Richter, S.; Kühna, J.; Schalley, C.A.; Unger, W.E.S. Evidence of click and coordination reactions on a self-assembled monolayer by synchrotron radiation based XPS and NEXAFS. J. Electron Spectrosc. Relat. Phenom. 2012, 185, $85-89$.

23. Zorn, G.; Liu, L.H.; Árnadóttir, L.; Wang, H.; Gamble, L.J.; Castner, D.G.; Yan, M. X-ray Photoelectron Spectroscopy Investigation of the Nitrogen Species in Photoactive Perfluorophenylazide-Modified Surfaces. J. Phys. Chem. C 2014, 118, 376-383.

24. Brosnan, S.M.; Brown, A.H.; Ashby, V.S. It Is the Outside That Counts: Chemical and Physical Control of Dynamic Surfaces. J. Am. Chem. Soc. 2013, 135, 3067-3072. 
25. Cimenez, V.; Mantecon, A.; Cadiz, V. Modification of Poly(vinyl alcohol) with Acid Chlorides and Crosslinking with Difunctional Hardeners. J. Polym. Sci. Part A 1996, 34, 925-934.

(C) 2015 by the authors; licensee MDPI, Basel, Switzerland. This article is an open access article distributed under the terms and conditions of the Creative Commons Attribution license (http://creativecommons.org/licenses/by/4.0/). 